\title{
Physiological, Histological, and Molecular Analyses of Avocado Mesocarp Fatty Acids During Fruit Development
}

\author{
Yu Ge${ }^{1}$, Xiangshu Dong ${ }^{2}$, Bin $\mathrm{Wu}^{1}$, Zining $\mathrm{Xu}^{1}$, Zhaoxi Zhou ${ }^{1}$, Xinge Lin ${ }^{1}$, Jiasui Wang ${ }^{1}$, \\ Xiaoping Zang ${ }^{1} \&$ Weihong $\mathrm{Ma}^{1}$ \\ ${ }^{1}$ Haikou Experimental Station, Chinese Academy of Tropical Agricultural Sciences, Hainan, China \\ ${ }^{2}$ College of Agriculture, Yunnan University, Yunnan, China \\ Correspondence: Yu Ge, Haikou Experimental Station, Chinese Academy of Tropical Agricultural Sciences, \\ Hainan, China. Tel: 86-0898-6677-0005. E-mail: geyu@catas.cn
}

Weihong Ma, Haikou Experimental Station, Chinese Academy of Tropical Agricultural Sciences, Hainan, China. Tel: 86-0898-6677-3067. E-mail: zjwhma@163.com

Received: September 1, 2018

Accepted: October 12, $2018 \quad$ Online Published: December 15, 2018

doi:10.5539/jas.v11n1p95

URL: https://doi.org/10.5539/jas.v11n1p95

The research is financed by the National Natural Science Foundation of China (Grant No. 31701883) and the Central Public-interest Scientific Institution Basal Research Fund for Chinese Academy of Tropical Agricultural Sciences (Grant No. 1630092018003).

\begin{abstract}
Fatty acids are important components of the avocado mesocarp, so a better understanding of how their change during fruit development will contribute to improving the quality of avocado fruits and their nutritional value. The changes in fatty acids, lipid droplets, and expression of some key genes and regulators participating in late glycolysis and fatty acid biosynthesis were analyzed at different stages of the development of avocado mesocarp. The total fatty acid contents of the avocado mesocarp increased during fruit development, with an increase by a factor of seven (from 1,628.04 to $11,116.30 \mathrm{mg} / 100 \mathrm{~g}$ dry weight) in the late stage of fruit maturation, this was confirmed by the changes observed in the lipid droplets. The composition of the main fatty acids varied at four developmental stages of fruit development. Palmitic, palmitoleic, oleic, and linoleic acid contents generally increased during fruit development, reaching maxima at Harvest, with percentages of total fatty acids of $50 \%$, 9\%, 31\%, and 8\%, respectively. Meanwhile, the amount of PaWRI1, PaACP4-2, and PapPK- $\beta 1$ expressed consistently increased by up to 4-fold during fruit development. This comprehensive analysis has indicated that the changes in the expressions of PaWRI1, PaACP4-2, and PapPK- $\beta 1$ were consistent with those in the total fatty acid contents, so they might have key roles in the accumulation of oil in the avocado mesocarp.
\end{abstract}

Keywords: lipid droplets, palmitic, PaWRI1, PaACP4-2, PapPK- $\beta 1$

\section{Introduction}

The fatty acids in avocado fruit are crucial constituents of their taste and possess the critical influence in keeping their quality and ensuring their nutritional value (Dreher \& Davenport, 2013). Any changes in the essence and concentrations of these compositions in avocado fruit are important because of their effect on sensory properties. Hence, plant physiologists and molecular biologists express an interest in examining these changes during the development of the edible portions of the fruit, owing to their impact on the market quality of the food product (Donetti \& Terry, 2014; Kilaru et al., 2015).

Avocado is among the most economically important subtropical/tropical fruit crop in the world, and increases in production are apparent throughout the world, with Mexico, the USA, Indonesia, Chile, Spain, Israel, Colombia, South Africa and Australia's growth in production being considerable (Schaffer et al., 2012). In terms of oil content, avocado fruit is surpassed only by oil palm and olive fruits (Knothe, 2013). The lipid content of avocado can range from $1 \%$ to $30 \%$ of the fruit, depending on the season, cultivar, and planting conditions (Rodríguez-Carpena et al., 2011; Vinha et al., 2013; Galvão et al., 2014). Avocado fruit lipids contain from 50\% to $60 \%$ monounsaturated fatty acids and $10 \%$ to $15 \%$ polyunsaturated, which are good for human health (Donetti \& Terry, 2014; Galvão et al., 2014; Pedreschi et al., 2016). 
Most of the genes governing late glycolysis and fatty acid synthesis might be co-regulated by the same cis- and trans-regulatory elements, and the discovery of the Arabidopsis wrinkledl (wril) mutant establish a crucial landmark in the verification of this assumption (Focks \& Benning, 1998). Recently, the transcription amounts of fatty acid and glycolytic biosynthetic genes have been found to correlate with the amount of WRII transcripts and the oil content of Arabidopsis thaliana (Baud et al., 2007, 2009, 2010), maize (Shen et al., 2010; Pouvreau et al., 2011), castor (Adhikari et al., 2016), Brassica napus (Wu et al., 2014; Li et al., 2015), cotton (Qu et al., 2012), potato (Hofvander et al., 2016), sugarcane (Zale et al., 2016), Nicotiana benthamiana (Vanhercke et al., 2014; Grimberg et al., 2015; Reynolds et al., 2015), and oil palm (Bourgis et al., 2011; Tranbarger et al., 2011; Dussert et al., 2013). Furthermore, the fatty acid and late glycolysis biosynthetic genes such as $A C P 4$ and $p P K-\beta 1$ have been shown to be regulated by WRI1 by binding to their promoter sequences (Baud et al., 2007, 2009; Pouvreau et al., 2011; Wu et al., 2014; Li et al., 2015). A study of the transcriptome of avocado mesocarp has also revealed that WRII and its isoform, WRI2, were highly expressed and correlated with oil accumulation (Kilaru et al., 2015).

Today, increasing numbers of consumers are not only seeking a smooth-tasting avocado variety, but also health-motivating substances, such as fatty acids. Even so, although several studies have detected and analyzed the fatty acid contents of various avocado varieties (Vinha et al., 2013; Galvão et al., 2014; Ge et al., 2017a, $2017 \mathrm{~b}, 2017 \mathrm{c}$ ), there is little information on the changes of fatty acids at different stages of avocado mesocarp development. Hence, the objective of the present research was to evaluate the variations in the content and type of fatty acids, visualize the lipid droplets, and analyze the expression of some key genes and regulators participating in fatty acid and late glycolysis biosynthesis at four stages of avocado mesocarp development. Our results will offer available data to help understanding the changes of avocado mesocarp fatty acids during fruit development from physiological, histological, and molecular analyses.

\section{Materials and Methods}

\subsection{Plant Material, Reagents, and Sample Preparation}

The avocado variety 'Guikenda No. 2' (Persea americana var. guatemalensis) were collected from six 10-year-old trees from the Chinese Academy of Tropical Agricultural Sciences (Danzhou city, Hainan province, China: location $19.52^{\circ} \mathrm{N}, 109.57^{\circ} \mathrm{E}$, altitude $=200 \mathrm{~m}$ ). In these trees, fruits corresponding to the main flowering season, which occurred during Feb. 2017, were marked. The marked fruit samplings were collected at different stages of fruit development, based on their days after pollination (DAP), which were from the maximum of one week after the end of second physiological fruit-dropping to physiological fruit maturity (defined as the ability to ripen after harvest). The four stages of fruit development were $65,85,105$, and $125 \mathrm{DAP}$ at harvest point, when the mesocarp dry matter was $\geq 21.5 \%$ based on the criterion according to Medina-Carrillo et al. (2017). The biological replicates included three units, each with two plants, and three biological replicates were measured in each developmental stage. The 18 marked fruit samples in each biological replicate for each developmental stage were randomly collected and immediately transported to the laboratory in standard foam boxes used for export packaging. The fruit samples were maintained at $5{ }^{\circ} \mathrm{C}$. The mesocarp was separated from the fruit, homogenized using a domestic blender, and then stored at $4{ }^{\circ} \mathrm{C}$ for a maximum of one week before analysis.

\subsection{Morphological Characteristics and Mass Assay}

The morphological measurements was length and diameter of fruits. Dry weights of avocado mesocarp were measured from fresh mesocarp samples separated and placed in an air dry oven (GZX-9146 MBE, Shanghai, China) at $105^{\circ} \mathrm{C}$ for $6 \mathrm{~h}$.. The measurements were performed on 18 fruits in each biological replicate with three biological replicates for each developmental stage.

\subsection{Extraction and Determination of Fatty Acids}

The oil was extracted and fatty acid profiles were detected according to Ge et al. (2017a). The oils extracted from avocado pulp and seed $(40 \mu \mathrm{L})$ were saponified at $80^{\circ} \mathrm{C}$ for 30 min after addition of $5 \mathrm{~mL} \mathrm{NaOH}-\mathrm{MeOH}$ $(0.2 \mathrm{~mol} / \mathrm{L})$. After cooling, the solutions were mixed with $2.5 \mathrm{~mL} \mathrm{BF}-\mathrm{MeOH}(14 \%)$ and incubated at $80^{\circ} \mathrm{C}$ for 30 min to produce methyl esters of the fatty acids. Following this, $2 \mathrm{~mL}$ of saturated $\mathrm{NaCl}$ and $4 \mathrm{~mL} n$-hexane were added, and the resulting solutions were refluxed for $15 \mathrm{~min}$. The upper layers were then removed, filtered through $0.22 \mu \mathrm{m}$ membranes, and used for fatty acid GC-MS analyses. The analyses were performed using an Agilent 7890B-7000B GC-MS (Santa Clara, CA, USA) equipped with a DB-5MS column $(60 \mathrm{~m} \times 0.25 \mathrm{~mm}$ i.d., $0.25-\mu \mathrm{m}$ film thickness) using helium $(1.3 \mathrm{~mL} / \mathrm{min})$ as the carrier gas. The fatty acid methyl esters (FAMEs) were identified by comparing the retention times of the peaks with those of commercial standards and comparing the respective ion chromatograms with those reported in the NIST 2011 library. Methyl nonadecanoate was added as an internal standard and the FAMEs were quantified using the calibration curves of the standards $\left(R^{2} \geq\right.$ 
0.995). The contents of the FAMEs, expressed as $\mathrm{mg} / 100 \mathrm{~g} \mathrm{DW}$, were presented as the mean \pm standard deviation of three biological replicates with two technical replicates of each.

\subsection{Histological Analyses}

The tissue samples were sectioned to a thickness of 10 to $15 \mu \mathrm{m}$ using a vibratome (CV5030, Leica Biosystems, Wetzlar, Germany), washed three times with $0.2 \mathrm{M}$ phosphate-buffered saline then stained with $0.5 \mu \mathrm{g} / \mathrm{mL}$ Nile red for the pulp. To prepare the Nile red solutions for staining, Nile red powder $(10 \mathrm{mg})$ was dissolved in $10 \mathrm{~mL}$ acetone then diluted to concentrations of 0.5 and $5 \mu \mathrm{g} / \mathrm{mL}$ with distilled water. The tissue samples were observed using confocal microscopy (Zeiss LM510, Carl Zeiss AG, Oberkochen, Germany) with laser excitation at 543 $\mathrm{nm}$ and a $40 \times$ objective lens and the lipid droplets in the mesocarp were identified

\subsection{RNA Extraction and Quantitative Real-Time PCR}

Total RNA was extracted from the mesocarp at the four stages using RNAiso Plus Reagent (TaKaRa Bio Inc., Kusatsu, Japan) based on the manufacturer's protocol, then treated with RNase-free DNase I (New England Biolabs, Ipswich, MA, USA) to eliminate all contaminating DNA. The resulting RNA was applied for first strand synthesis by the PrimeScript RT reagent Kit with gDNA Eraser (TaKaRa Bio Inc.). Five genes were selected for gene expression analysis: PaWRI1 (wrinkled1), PaWRI2 (wrinkled2), PapPK- $\beta 1$ (plastidic pyruvate kinase beta subunit 1), PaACP4-1 (acyl carrier protein 4-1), and PaACP4-2 (acyl carrier protein 4-2). PaActin7 was used as an endogenous control for standardization. The sequences of these genes were chosen from Additional file 2: Data S1 (Kilaru et al., 2015). Gene-specific primers were developed through the Primer Premier 5.0 (Premier Biosoft International, Palo Alto, CA, USA) and were synthesized by IDT (Integrated DNA Technologies, Coralville, IA, USA). The primers were developed to amplify a product of no more than $170 \mathrm{bp}$ with melting temperatures $\left(\mathrm{T}_{\mathrm{m}}\right)$ of $55{ }^{\circ} \mathrm{C}$ (Table 1). The concentration of cDNA was determined and diluted to $12.5 \mathrm{ng} / \mu \mathrm{L}$. PCR was performed using QuantStudio 7 Flex Real Time PCR System (Applied Biosystems, Foster City, CA, USA). The reactions were arranged in a total volume of $20 \mu \mathrm{l}$ including $2 \mu \mathrm{l}$ cDNA, $10 \mu \mathrm{l}$ of SYBR Premix Ex Tap II (Tli RNaseH Plus) (TaKaRa Bio Inc.), $1.0 \mu \mathrm{l}$ of each $10 \mu \mathrm{M}$ primer, and $6 \mu$ distilled water. The quantitative real-time PCR conditions were as follows: one cycle of $95^{\circ} \mathrm{C}$ for $5 \mathrm{~min}, 33$ cycles of $95{ }^{\circ} \mathrm{C}$ for $25 \mathrm{~s}, \mathrm{~T}_{\mathrm{m}}$ of each primer for $50 \mathrm{~s}$, and $72{ }^{\circ} \mathrm{C}$ for $3 \mathrm{~min}$. The final elongation was executed at $72{ }^{\circ} \mathrm{C}$ for $10 \mathrm{~min}$. The relative expression value of each gene was counted according to the $2^{-\Delta \Delta \mathrm{Ct}}$ method for relative quantification (Livak \& Schmittgen, 2001). Data are presented as means \pm SD of three biological reactions possessed in different 96-well plates, each having two replicates in each plate. The primers used for quantitative real-time PCR were presented in Table 1.

Table 1. Primers used for quantitative real-time PCR

\begin{tabular}{|c|c|c|c|c|}
\hline Gene ID & Gene name & Primer name & Sequence & Product size (bp) \\
\hline \multirow{2}{*}{ PA10049345 } & \multirow{2}{*}{ PaWRII } & Forward & 5'-CCGATATCGCCCTCGACAAA-3' & \multirow{2}{*}{105} \\
\hline & & Reverse & 5'-GAAAACCACCCTCAGCTCCA-3' & \\
\hline \multirow{2}{*}{ PA10035938 } & \multirow{2}{*}{ PaWRI2 } & Forward & 5'-CCTCGCAACATACTGAGCCA-3' & \multirow{2}{*}{106} \\
\hline & & Reverse & 5'-GCAGACTGTGCCAATATGCG-3' & \\
\hline \multirow{2}{*}{ PA 10009565} & \multirow{2}{*}{$P a p P K-\beta 1$} & Forward & 5'-AGCCGATCGAGAAGCTCAAG-3' & \multirow{2}{*}{102} \\
\hline & & Reverse & 5'-TAGGGACCGTACGGAAGGAT-3' & \\
\hline \multirow{2}{*}{ PA10004096 } & \multirow{2}{*}{ PaACP4-1 } & Forward & 5'-GCTGCTAAACCAGAGACGGT-3' & \multirow{2}{*}{157} \\
\hline & & Reverse & 5'-ATGCCTCTTCAAGCCCCATC-3' & \\
\hline \multirow{2}{*}{ PA10007942 } & \multirow{2}{*}{$\mathrm{PaACP} 4-2$} & Forward & 5'-ATCGAGCGAATCAGCACCAA-3, & \multirow{2}{*}{168} \\
\hline & & Reverse & 5'-TCAGTTAGGTTGCAGCCAGG-3' & \\
\hline \multirow{2}{*}{ PA10000748 } & \multirow{2}{*}{ PaActin 7} & Forward & 5'-ATACCTCTCTTGGACTGGGC-3' & \multirow{2}{*}{115} \\
\hline & & Reverse & 5'-CTCCACGGGCTGTGTTCC-3' & \\
\hline
\end{tabular}

Note. Gene IDs came from the Additional file 2: Data S1 (Kilaru et al., 2015).

\subsection{Statistical Analyses}

Data analyses were conducted through SPSS Statistics, version 20.0 (IBM Corp, Armonk, NY, USA). Significant differences were verified by one-way analysis of variance, and Duncan's multiple comparison test was used at $95 \%$ confidence level. The PCA were obtained using NTSYS pc 2.1 software. 


\section{Results and Discussion}

\subsection{Changes in Morphological Characteristics During Fruit Development}

Dry weight in the mesocarp increased significantly all the time from 9.45 to $54.75 \mathrm{~g}$ with fruit growth and development (Table 2). Length and diameter increased significantly with fruit growth and development (Table 2). Length and diameter increased rapidly during 65-105 DAP, and showed a relatively slow growth trend during 105-125 DAP. Length/diameter decreased in the earlier-middle stage and increased in the late stage (Table 2). Length/diameter reached the minimum value (1.33) at 105 DAP. Therefore, the growth of avocado fruit was mainly horizontal thickening during 65-105 DAP, and mainly longitudinal elongation during 105-125 DAP. Schaffer et al. (2012) suggested that the fruit shapes of the avocado cultivars was exceedingly rich around the world, such as Bacon and Hass for ovate, Ettinger for pyriform, and Fuerte for pyriform with a distinct neck, etc. Based on the fruit length/diameter in the present study, the mature fruit shape (1.40) of the avocado commercial variety "Guikenda No. 2" was almost ovate.

Table 2. Dry masses and fruit size and fruit length/diameter at four stages of fruit development

\begin{tabular}{lllll}
\hline \multirow{2}{*}{ Indicator } & \multicolumn{3}{c}{ Stage } \\
\cline { 2 - 5 } & 65 DAP & 85 DAP & 105 DAP & 125 DAP (Harvest) \\
\hline Mesocarp mass $(\mathrm{g})$ & $9.57 \pm 0.11 \mathrm{a}$ & $20.81 \pm 0.26 \mathrm{~b}$ & $36.91 \pm 0.53 \mathrm{c}$ & $54.75 \pm 0.64 \mathrm{~d}$ \\
Fruit length $(\mathrm{mm})$ & $66.65 \pm 1.06 \mathrm{a}$ & $91.45 \pm 0.90 \mathrm{~b}$ & $106.54 \pm 0.82 \mathrm{c}$ & $117.59 \pm 0.55 \mathrm{~d}$ \\
Fruit diameter $(\mathrm{mm})$ & $43.08 \pm 2.91 \mathrm{a}$ & $63.33 \pm 0.75 \mathrm{~b}$ & $80.32 \pm 0.86 \mathrm{c}$ & $83.77 \pm 0.78 \mathrm{~d}$ \\
Fruit length/diameter & $1.55 \pm 0.09 \mathrm{a}$ & $1.44 \pm 0.01 \mathrm{~b}$ & $1.33 \pm 0.00 \mathrm{c}$ & $1.40 \pm 0.01 \mathrm{~d}$ \\
\hline
\end{tabular}

Note. Error bars indicate standard deviation from 18 fruits in each biological replicate with three biological replicates. Means with the different letters indicate significant differences (Waller-Duncan, $P \leq 0.05$ ) among four developmental stages of each morphological trait.

\subsection{Changes in Total Fatty Acid and Lipid Droplets During Fruit Development}

Total fatty acid in the mesocarp increased with fruit development, with significant differences in content between the four stages of fruit development (Table 3). Total fatty acid content slowly increased in the mesocarp from 65 to $105 \mathrm{DAP}$, and then increased sharply, reaching the maximum of $11,116.30 \mathrm{mg} / 100 \mathrm{~g} \mathrm{DW}$ at $125 \mathrm{DAP}$. From 105 to $125 \mathrm{DAP}$, total fatty acid content in the mesocarp rose significantly from $1,628.05$ to $11,116.30 \mathrm{mg} / 100 \mathrm{~g}$ DW, a 7-fold increase, this was also found in the late developmental period of oil palm fruit (Bourgis et al., 2011; Tranbarger et al., 2011). Oil palm fruit possessed lipid-rich mesocarp tissue, which had 6- to 7-fold increases in the total fatty acids in the mid-to late stage of fruit development (Bourgis et al., 2011; Tranbarger et al., 2011; Dussert et al., 2013). Our results suggested that the period between 105 DAP and 125 DAP was a key time for forming fatty acids in the avocado mesocarp.

Table 3. Total fatty acid contents (mg/100 g DW) in avocado mesocarp at four stages of fruit development

\begin{tabular}{lllll}
\hline \multirow{2}{*}{ Indicator } & \multicolumn{4}{c}{ Stage } \\
\cline { 2 - 5 } & 65 DAP & 85 DAP & 105 DAP & 125 DAP (Harvest) \\
\hline Total fatty acid & $1002.09 \pm 38.42 \mathrm{a}$ & $1109.32 \pm 123.40 \mathrm{~b}$ & $1628.05 \pm 36.01 \mathrm{c}$ & $11116.30 \pm 684.69 \mathrm{~d}$ \\
\hline
\end{tabular}

Note. Error bars indicate standard deviation from three biological replicates with two technical replicates of each. Means with the different letters indicate significant differences (Duncan, $P \leq 0.05$ ) among four developmental stages.

The histological analyses were carried out to visualize the lipid droplets in the mesocarp during fruit development. The total fatty acid content increased from 1.00 to $1.63 \%$ of dry mass from 65 to 105 DAP, respectively (Table 3). Small lipid droplets (approximately $2 \mu \mathrm{m}$ in diameter; Figures 1A, 1B, and 1C) were present throughout the periphery of the cells. At 125 DAP, a great many large lipid droplets $(10-25 \mu \mathrm{m}$ in diameter; Figure 1D) had formed, occupying the volume of the most cell, when the total fatty acid content had risen to $11.12 \%$ of dry mass (Table 3). Our histological analyses verified the trend in total fatty acid content detected using GC-MS in the avocado mesocarp during fruit development in the present study. Our results agreed with those of Tranbarger et al. (2011) and Dussert et al. (2013) in that lipid droplets (approximately $2 \mu \mathrm{m}$ 
in diameter) accumulated within the periphery of the cells during the early to medium stages of development in the mesocarp of oil palm fruit, while larger lipid droplets (11-14 $\mathrm{mm}$ in diameter, 6 to 11 per mesocarp cell) occupied the cellular space during the late stage.
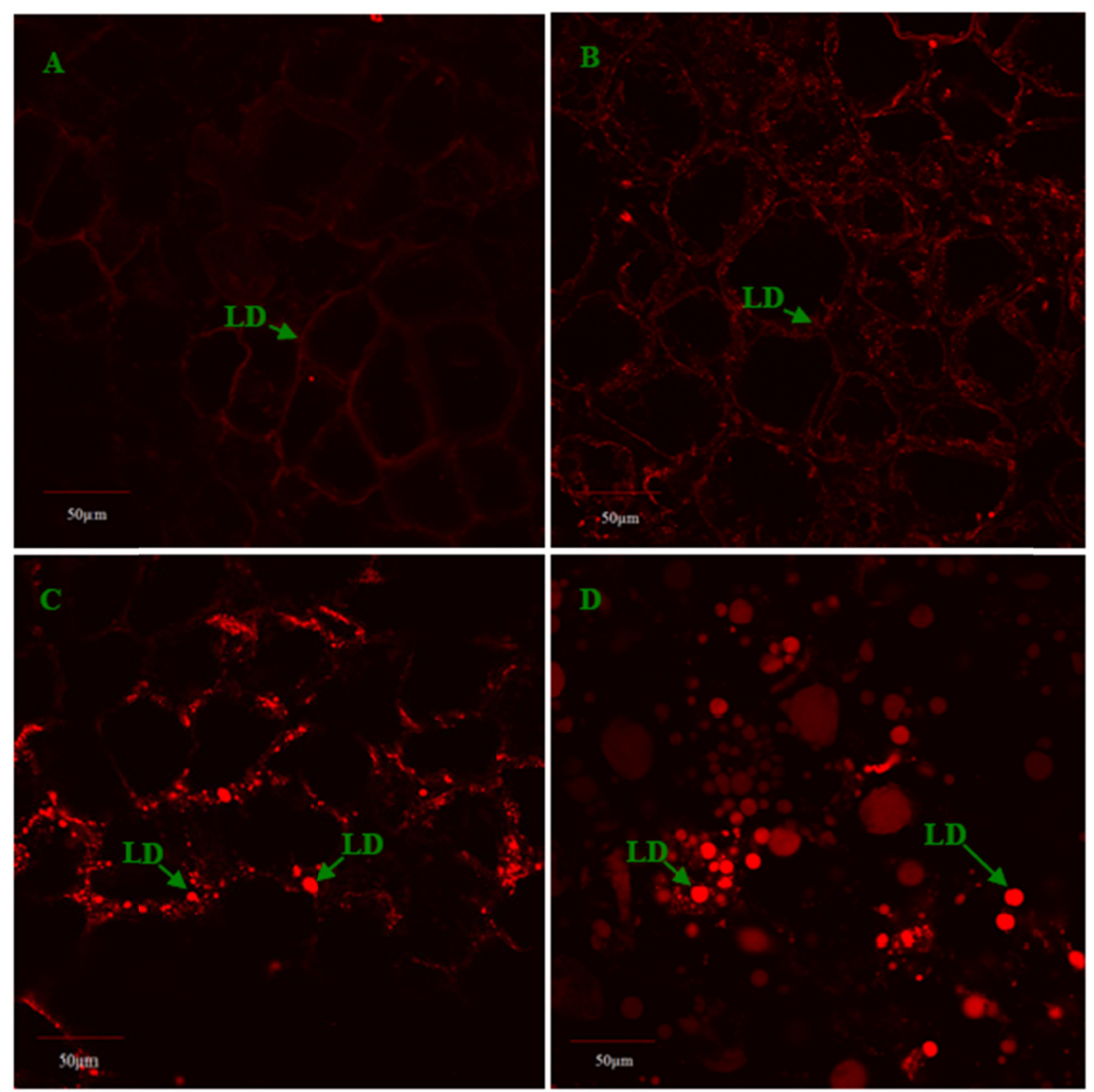

Figure 1. Confocal microscopy images of lipid droplets in avocado mesocarp at 65 (A), 85 (B), 105 (C), and 125 DAP (Harvest) (D) using Nile red staining. LD: lipid droplet

\subsection{Changes in Fatty Acid Composition During Fruit Development}

Eight fatty acids were detected by GC-MS in the mesocarp: myristic, palmitic, palmitoleic, stearic, oleic, linoleic, linolenic, and arachic acid (Table 4). The content of the eight fatty acids was significantly different between the four stages of fruit development except for arachidic acid (Table 4). The dominating of fatty acid compositions varied at the four stages of fruit development. From 65 to 85 DAP, the contents of fatty acids in order of abundance were: linoleic, palmitic, linolenic, oleic, palmitoleic, myristic, stearic, and arachidic acid. From 85 to 105 DAP, the order was palmitic, oleic, linoleic, linolenic, palmitoleic, stearic, myristic, and arachidic acid. From 105 to 125 DAP, the order was palmitic, oleic, palmitoleic, linoleic, stearic, myristic, arachidic, and linolenic acid. Over the whole fruit development period, the contents of the mainly fatty acids: palmitic, palmitoleic, oleic, linoleic, and linolenic acid, were in the ranges 335.21-5,597.97, 9.42-1,019.14, 0.00-3,413.14, 377.38-932.22, and $15.58-269.69 \mathrm{mg} / 100 \mathrm{~g} \mathrm{DW}$, respectively. 
Table 4. Fatty acid composition (mean value \pm standard deviation, $\mathrm{mg} / 100 \mathrm{~g} \mathrm{DW}$ ) of avocado mesocarp at four stages of fruit development

\begin{tabular}{lllll}
\hline \multirow{2}{*}{ Fatty acid } & \multicolumn{4}{c}{ Stage } \\
\cline { 2 - 5 } & 65 DAP & 85 DAP & 105 DAP & 125 DAP \\
\hline Myristic acid & $6.09 \pm 0.07 \mathrm{a}$ & $15.03 \pm 1.84 \mathrm{~b}$ & $4.69 \pm 0.15 \mathrm{c}$ & $10.68 \pm 0.46 \mathrm{~d}$ \\
Palmitic acid & $335.21 \pm 13.79 \mathrm{a}$ & $371.23 \pm 51.83 \mathrm{~b}$ & $603.28 \pm 10.99 \mathrm{c}$ & $5597.97 \pm 460.78 \mathrm{~d}$ \\
Palmitoleic acid & $9.42 \pm 0.43 \mathrm{a}$ & $27.19 \pm 3.93 \mathrm{~b}$ & $74.41 \pm 1.37 \mathrm{c}$ & $1019.14 \pm 68.93 \mathrm{~d}$ \\
Stearic acid & $4.71 \pm 0.17 \mathrm{a}$ & $11.93 \pm 1.84 \mathrm{~b}$ & $9.87 \pm 0.28 \mathrm{c}$ & $120.75 \pm 13.74 \mathrm{~d}$ \\
Oleic acid & nd & $51.27 \pm 3.91 \mathrm{a}$ & $511.49 \pm 11.30 \mathrm{~b}$ & $3413.14 \pm 110.04 \mathrm{c}$ \\
Linoleic acid & $377.38 \pm 14.14 \mathrm{a}$ & $397.99 \pm 38.45 \mathrm{~b}$ & $337.58 \pm 9.43 \mathrm{c}$ & $932.22 \pm 53.51 \mathrm{~d}$ \\
Linolenic acid & $269.69 \pm 10.43 \mathrm{a}$ & $233.83 \pm 23.75 \mathrm{~b}$ & $86.04 \pm 5.00 \mathrm{c}$ & $15.58 \pm 0.78 \mathrm{~d}$ \\
Arachidic acid & $0.40 \pm 0.01 \mathrm{a}$ & $0.85 \pm 0.09 \mathrm{~b}$ & $0.69 \pm 0.04 \mathrm{~b}$ & $6.82 \pm 1.39 \mathrm{c}$ \\
\hline
\end{tabular}

Note. Error bars indicate standard deviation from three biological replicates with two technical replicates of each. Means with different letters in the same horizontal row indicate significant differences (Duncan, $P \leq 0.05$ ). nd $=$ not detected.

During fruit growth and development, the concentration of palmitic and palmitoleic acids gradually increased from 65 to 105 DAP followed by a rapid increase until 125 DAP, reaching maxima of 5,597.97 and 1,019.14 $\mathrm{mg} / 100 \mathrm{~g}$ DW, respectively. The oleic acid content started to increase after $85 \mathrm{DAP}$, and then increased dramatically by 70 times from $51.27 \mathrm{mg} / 100 \mathrm{~g} \mathrm{DW}$ at 85 DAP to $3,413.14 \mathrm{mg} / 100 \mathrm{~g}$ DW at $125 \mathrm{DAP}$. The linoleic acid content fluctuated during fruit development, ultimately achieving a maximum of $932.22 \mathrm{mg} / 100 \mathrm{~g}$ DW at 125 DAP. From 65 to 85 DAP, the linoleic acid content was higher than those of the other fatty acids, but the linolenic acid content declined constantly during fruit development and ultimately could reach a minimum of $15.58 \mathrm{mg} / 100 \mathrm{~g}$ DW at $125 \mathrm{DAP}$.

The present study suggested that the main fatty acid components of the avocado mesocarp were also reported that these the same acids were often the dominant fatty acids in mature avocado fruit (Ferreyra et al., 2016; Pedreschi et al., 2016; Rohman et al., 2016; Ge et al., 2017a, 2017b, 2017c; Zhu et al., 2017). Previous studies have demonstrated that the palmitic acid content usually declined, while oleic and linoleic acids usually increased during the development of almonds (Zhu et al., 2017), walnuts (Chen et al., 2016a, 2016b), and borage (Guo et al., 2016), which results did not agree with those of this study. Our results demonstrated that the content of palmitic, oleic, and linoleic acids all increased during the four stages of fruit development, reaching maxima at the late stage.

The PCA results of eight fatty acids in avocado mesocarp at four stages of fruit development were obtained using NTSYS pc 2.1 software and were shown in Figure 2. PCA generalized eight fatty acids to two principal components which accounted for $96.83 \%$ of the total variation. The first component F1 explained $83.12 \%$ of the total variation and was mainly associated with palmitoleic acid, palmitic acid, stearic acid, oleic acid, arachic acid, linoleic acid, and linolenic acid. The second component F2 accounted for $13.71 \%$ of the total variation and was fundamentally defined by myristic acid. 


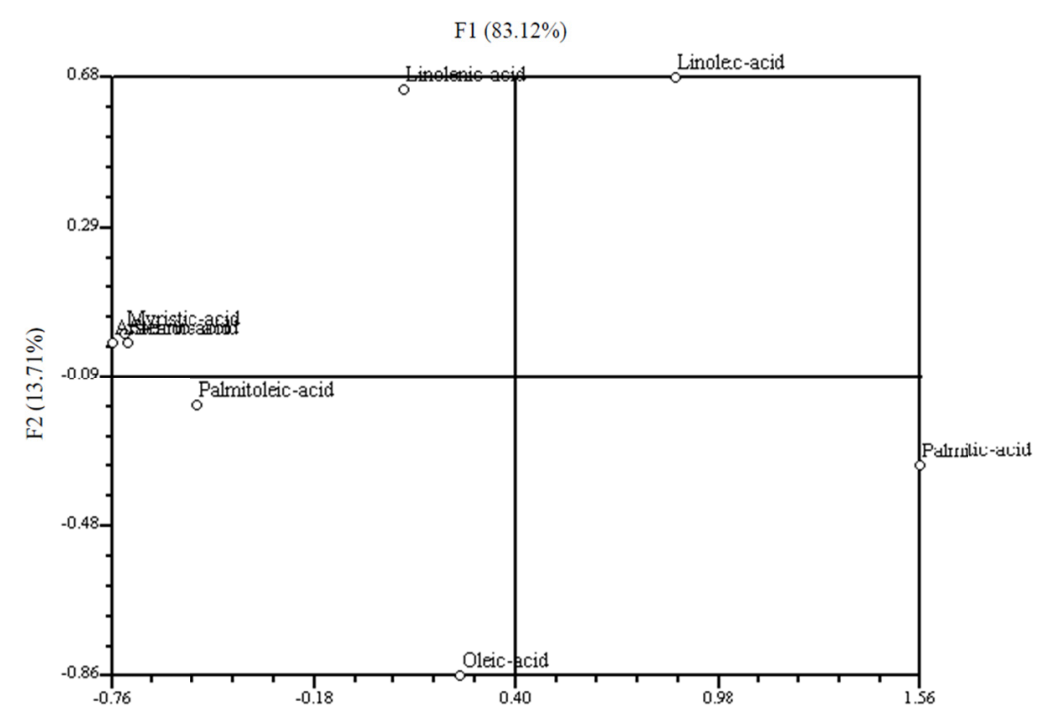

Figure 2. Diagram showing the relationships among eight fatty acids in avocado mesocarp at four stages of fruit development based on principal component analysis

\subsection{Changes in Fatty Acid-related Genes During Fruit Development}

The expression of PaWRI1, PaACP4-1, PaACP4-2, and PapPK- $\beta 1$ were increasingly expressed during fruit development, reaching maxima at 125 DAP (Figure 3). The amounts of PaWRI1, PaACP4-2, and PapPK- $\beta 1$ expression increased 4-fold from 65 to $125 \mathrm{DAP}$, and exhibited significant differences among the four stages of fruit development, while those of PaACP4-1 expression increased by only half between 1 at 65 DAP and 1.42 at 125 DAP. The expression of PaWRI2 decreased slowly from 65 to 85 DAP, and then increased slightly until 125 DAP, overall increasing by a half during the four stages of fruit development (Figure 3 ). The changes in the expression of $P a W R I 1, P a A C P 4-2$, and PapPK- $\beta 1$ were consistent with changes in the total fatty acid content in the present study, while those of PaACP4-1 and PaWRI2 were inconsistent. These results suggested that PaWRI1, PaACP4-2, and PapPK- $\beta 1$ might play key roles in accumulating oil in the avocado mesocarp, which agreed with the results of Kilaru et al. (2015). However, in the present study, the pattern of change in the expression of PaWRI2 differed from that of change in total fatty acid content, which indicated that PaWRI2 might not influence oil accumulation. By contrast, using transcriptome analysis, Kilaru et al. (2015) suggested that PaWRI2 might play a role in oil accumulation for additional transcription factors in avocado mesocarp.

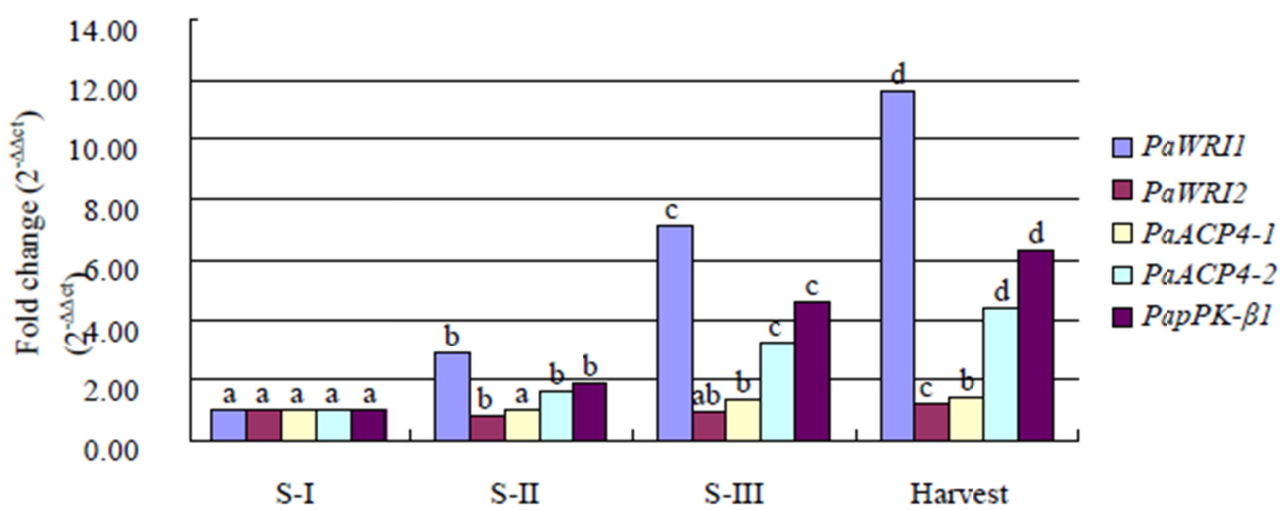

Figure 3. Relative expression patterns of PaWRI1, PaWRI2, PaACP4-1, PaACP4-2, and PapPK- $\beta 1$ in avocado mesocarp at four stages of fruit development. Relative expression levels were normalized to that of PaActin 7 and are presented relative to S-I in the avocado mesocarp. Error bars indicate standard deviation from three biological replicates with each having two technical replicates. Means with the different letters indicate significant differences (Duncan, $P \leq 0.05$ ) among four developmental stages of each gene 
Our results indicated that the pattern of changes in the expression of PaWRII was consistent with those of PaACP4-2 and PapPK- $\beta 1$, which also agreed with Kilaru et al. (2015) where transcriptome analysis of avocado mesocarp indicated that the expressions of PaWRI1, PaACP4, and PapPK- $\beta 1$ had the same pattern of changes. Therefore, it could be inferred that PaWRI1 might up-regulate PaACP4-2, and PapPK- $\beta 1$ in the avocado mesocarp in this study.

\section{Conclusion}

The content of total fatty acid of the avocado mesocarp increased during fruit development, and a remarkable increase in the total fatty acids was found in the late stage. For the main fatty acid compositions, palmitic, palmitoleic, oleic, and linoleic acids contents generally increased during fruit development, reaching maxima at the late stage. The expression amount of PaWRI1, PaACP4-2, and PapPK- $\beta 1$ consistently increased by up to 4-fold during fruit development. The comprehensive analysis has indicated that the changes in the expression of PaWRI1, PaACP4-2, and PapPK- $\beta 1$ were consistent with those in the total fatty acid content, and PaWRII gene could possess a key action in regulating the biosynthesis of fatty acids in the avocado mesocarp.

\section{Acknowledgements}

This work was supported by the National Natural Science Foundation of China (Grant No. 31701883) and the Central Public-interest Scientific Institution Basal Research Fund for Chinese Academy of Tropical Agricultural Sciences (Grant No. 1630092018003).

\section{References}

Adhikari, N. D., Bates, P. D., \& Browse, J. (2016). WRINKLED1 rescues feedback inhibition of fatty acid synthesis in hydroxylase-expressing seeds. Plant Physiology, 171, 179-191. https://doi.org/10.1104/pp.15. 01906

Baud, S., Bourrellier, A. B. F., Azzopardi, M., Berger, A., Dechorgnat, J., Daniel-Vedele, F., ... Ferrario-Mery, S. (2010). PII is induced by WRINKLED1 and fine-tunes fatty acid composition in seeds of Arabidopsis thaliana. Plant Journal, 64, 291-303. https://doi.org/10.1111/j.1365-313X.2010.04332.x

Baud, S., Mendoza, M. S., To, A., Harscoet, E., Lepiniec, L., \& Dureucq, B. (2007). WRINKLED1 specifies the regulatory action of LEAFY COTYLEDON2 towards fatty acid metabolism during seed maturation in Arabidopsis. Plant Journal, 50, 825-838. https://doi.org/10.1111/j.1365-313X.2007.03092.x

Baud, S., Wuilleme, S., To, A., Rochat, C., \& Lepiniec, L. (2009). Role of WRINKLED1 in the transcriptional regulation of glycolytic and fatty acid biosynthetic genes in Arabidopsis. Plant Journal, 60, 933-947. https://doi.org/10.1111/j.1365-313X.2009.04011.x

Bourgis, F., Kilaru, A., Cao, X., Ngando-Ebongue, G. F., Drira, N., Ohlrogge, J. B., \& Arondel, V. (2011). Comparative transcriptome and metabolite analysis of oil palm and date palm mesocarp that differ dramatically in carbon partitioning. Proceedings of the National Academy of Sciences of the United States of America, 108, 12527-12532. https://doi.org/10.1073/pnas.1106502108

Chen, H., Pan, C. D., Wang, B., Hu, Y., Xiao, Z. Z., \& He, M. (2016a). The relationship among nutrients accumulation and dynamic changes of fatty acids in seed development of walnut. Journal of Agricultural University Hebei, 39, 57-74.

Chen, W. J., Liu, X. R., Deng, Q. J., Peng, F. R., He, H. Y., \& Li, X. F. (2016b). Nut development and fatty acid accumulation in Carya illinoensis. Nonwood Forest Research, 34, 50-55.

Donetti, M., \& Terry, L. A. (2014). Biochemical markers defining growing area and ripening stage of imported avocado fruit cv. Hass. Journal of Food and Composition Analysis, 34, 90-98. https://doi.org/10.1016/ j.jfca.2013.11.011

Dreher, M. L., \& Davenport, A. J. (2013). Hass avocado composition and potential health effects. Critical Reviews in Food Science and Nutrition, 53, 738-750. https://doi.org/10.1080/10408398.2011.556759

Dussert, S., Guerin, C., Andersson, M., Joet, T., Tranbarger, T. J., Pizot, M., ... Morcillo, F. (2013). Comparative transcriptome analysis of three oil palm fruit and seed tissues that differ in oil content and fatty acid composition. Plant Physiology, 162, 1337-1358. https://doi.org/10.1104/pp.113.220525

Ferreyra, R., Selles, G., \& Saavedra, J. (2016). Identification of pre-harvest factors that affect fatty acid profiles of avocado fruit (Persea americana Mill) cv. 'Hass' at harvest. South African Journal of Botany, 104, 15-20. https://doi.org/10.1016/j.sajb.2015.10.006 
Focks, N., \& Benning, C. (1998). wrinkled1: A novel, low-seed-oil mutant of Arabidopsis with a deficiency in the seed-specific regulation of carbohydrate metabolism. Plant Physiology, 118, 91-101. https://doi.org/ 10.1104/pp.118.1.91

Galvão, M. D. S., Narain, N., \& Nigam, N. (2014). Influence of different cultivars on oil quality and chemical characteristics of avocado fruit. Food Science and Technology, 34, 539-546. https://doi.org/10.1590/ $1678-457 \times .6388$

Ge, Y., Ma, F. N., Han, W. B., Wang, J. S., Hu, F. C., Zang, X. P., \& Ma, W. H. (2017c). Identification of fatty acid components in avocado fruit by gas chromatography-mass spectrometry. Chinese Journal Tropical Agriculture, 37, 1-6.

Ge, Y., Si, X. Y., Cao, J. Q., Zhou, Z. X., Wang, W. L., \& Ma, W. H. (2017a). Morphological characteristics, nutritional quality, and bioactive constituents in fruits of two avocado (Persea americana) varieties from hainan province, China. Journal of Agricultural Science, 9, 8-17.

Ge, Y., Si, X. Y., Hu, F. C., Xiong, S. K., Zang, X. P., \& Ma, W. H. (2017b). Fatty acid content in pulp of seven Persea Americana varieties (lines) and the correlations. Journal of Guizhou Agricultural Science, 45, 104-108.

Grimberg, Å., Carlsson, A. S., Marttila, S., Bhalerao, R., \& Hofvander, P. (2015). Transcriptional transitions in Nicotiana benthamiana leaves upon induction of oil synthesis by WRINKLED1 homologs from diverse species and tissues. BMC Plant Biology, 15, 192. https://doi.org/10.1186/s12870-015-0579-1

Guo, X., Zhang, J., Wang, W. T., Liu, C., Chen, A. W., \& Sun, J. Y. (2016). Changes of fatty acid components in the developing seeds of Borago. Journal Nuclear Agricultural Science, 30, 1947-1951.

Hofvander, P., Ischebeck, T., Turesson, H., Kushwaha, S. K., Feussner, I., Carlsson, A. S., \& Andersson, M. (2016). Potato tuber expression of Arabidopsis WRINKLED1 increases triacylglycerol and membrane lipids while affecting central carbohydrate metabolism. Plant Biotechnology Journal, 14, 1-16. https://doi.org/ $10.1111 /$ pbi. 12550

Kilaru, A., Cao, X., Dabbs, P. B., Sung, H. J., Rahman, M. M., Thrower, N., ... Ohlrogge, J. B. (2015). Oil biosynthesis in a basal angiosperm: transcriptome analysis of Persea Americana mesocarp. BMC Plant Biology, 15, 203. https://doi.org/10.1186/s12870-015-0586-2

Knothe. (2013). Avocado and olive oil methyl esters. Biomass and Bioenergy, 58, 143-148. https://doi.org/ 10.1016/j.biombioe.2013.09.003

Li, Q., Shao, J. H., Tang, S. H., Shen, Q. W., Wang, T. H., Chen, W. L., \& Hong, Y. Y. (2015). Wrinkled1 accelerates flowering and regulates lipid homeostasis between oil accumulation and membrane lipid anabolism in Brassica napus. Frontiers in Plant Science, 6, 1015. https://doi.org/10.3389/fpls.2015.01015

Livak, K. J., \& Schmittgen, T. D. (2001). Analysis of relative gene expression data using real-time quantitative PCR and the $2^{-\Delta \Delta C T}$ method. Methods, 25, 402-408. https://doi.org/10.1006/meth.2001.1262

Medina-Carrillo, R. E., Salazar-Garcia, S., Bonilla-Cardenas, J. A., Herrera-Gonzalez, J. A., Ibarra-Estrada, M. E., \& Alvarez-Bravo, A. (2017). Secondary metabolites and lignin in'Hass' avocado fruit skin during fruit development in three producing regions. Hortscience, 52, 852-858. https://doi.org/10.21273/HORTSCI1 1882-17

Pedreschi, R., Hollak, S., Harkema, H., Otma, E., Robledo, P., \& Somhorst, D. (2016). Impact of postharvest ripening strategies on 'Hass' avocado fatty acid profiles. South African Journal of Botany, 103, 32-35. https://doi.org/10.1016/j.sajb.2015.09.012

Pouvreau, B., Baud, S., Vernoud, V., Morin, V., Py, C., Gendrot, G., ... Rogowsky, P. M. (2011). Duplicate maize Wrinkled1 transcription factors activate target genes involved in seed oil biosynthesis. Plant Physiology, 156, 674-686. https://doi.org/10.1104/pp.111.173641

Qu, J., Ye, J., Geng, Y. F., Sun, Y. W., Gao, S. Q., Zhang, B. P., ... Chua, N. H. (2012). Dissecting functions of KATANIN and WRINKLED1 in cotton fiber development by virus-induced gene silencing. Plant Physiology, 160, 738-748. https://doi.org/10.1104/pp.112.198564

Reynolds, K. B., Taylor, M. C., Zhou, X. R., Vankercke, T., Wood, C. C., Blanchard, C. L., ... Petrie, J. R. (2015). Metabolic engineering of medium-chain fatty acid biosynthesis in Nicotiana benthamiana plant leaf lipids. Frontiers in Plant Science, 6, 164. https://doi.org/10.3389/fpls.2015.00164 
Rodríguez-Carpena, J. G., Morcuende, D., Andrade, M. J., Kylli, P., \& Estevez, M. (2011). Avocado (Persea americana Mill.) phenolics, in vitro antioxidant and antimicrobial activities, and inhibition of lipid and protein oxidation in porcine patties. Journal of Agricultural and Food Chemistry, 59, 5625-5635. https://doi.org/10.1021/jf1048832

Rohman, A., Windarsih, A., Riyanto, S., Sudjadi, G., Ahmad, S. A. S., Rosman, A. S., \& Yusof, F. M. (2016). Fourier transforms infrared spectroscopy combined with multivariate calibrations for the authentication of avocado oil. International Journal of Food Properties, 19, 680-687. https://doi.org/10.1080/10942912. 2015.1039029

Schaffer, B., Wolstenholme, B. N., \& Whiley, A. W. (2012). The Avocado: Botany, Production and Uses (2nd ed.). Croydon, CD: CPI Group (UK) Ltd.

Shen, B., Allen, W. B., Zheng, P. Z., Li, C. J., Glassman, K., Ranch, J., ... Tarczynski, M. C. (2010). Expression of ZmLEC1 and ZmWRII increases seed oil production in maize. Plant Physiology, 153, 980-987. https://doi.org/10.1104/pp.110.157537

Tranbarger, T. J., Dussert, S., Joet, T., Argout, X., Summo, M., Champion, A., ... Morcillo, F. (2011). Regulatory mechanisms underlying oil palm fruit mesocarp maturation, ripening, and functional specialization in lipid and carotenoid metabolism. Plant Physiology, 156, 564-584. https://doi.org/10.1104/pp.111.175141

Vanhercke, T., Tahchy, A. E., Liu, Q., Zhou, X. R., Shrestha, P., Divi, U. K., ... Petrie, J. R. (2014). Metabolic engineering of biomass for high energy density: oilseed-like triacylglycerol yields from plant leaves. Plant Biotechnology Journal, 12, 231-239. https://doi.org/10.1111/pbi.12131

Vinha, A. F., Moreira, J., \& Barreira, S. V. P. (2013). Physicochemical parameters, phytochemical composition and antioxidant activity of the Algarvian avocado (Persea americana Mill.). Journal of Agricultural Science, 5, 100-109. https://doi.org/10.5539/jas.v5n12p100

Wu, X. L., Liu, Z. H., Hu, Z. H., \& Huang, R. Z. (2014). BnWRII coordinates fatty acid biosynthesis and photosynthesis pathways during oil accumulation in rapeseed. Journal of Integrative Plant Biology, 56, 582-593. https://doi.org/10.1111/jipb.12158

Zale, J., Jung, J. H., Kim, J. K., Pathak, B., Karan, R., Liu, H., ... Altpeter, F. (2016). Metabolic engineering of sugarcane to accumulate energy-dense triacylglycerols in vegetative biomass. Plant Biotechnology Journal, 14, 661-669. https://doi.org/10.1111/pbi.12411

Zhu, Y., Wilkinson, K. L., \& Wirthensohn, M. (2017). Changes in fatty acid and tocopherol content during almond (Prunus dulcis, cv. Nonpareil) kernel development. Scientia Horticulturae, 225, 150-155. https://doi.org/10.1016/j.scienta.2017.07.008

\section{Copyrights}

Copyright for this article is retained by the author(s), with first publication rights granted to the journal.

This is an open-access article distributed under the terms and conditions of the Creative Commons Attribution license (http://creativecommons.org/licenses/by/4.0/). 